\title{
Love Motels: Oriental Phenomenon or emergent sector?
}

\section{Abstract}

Purpose

This study explores the 'Love Motel' concept by examining the changing attitude of consumers in Taiwan. This will increase knowledge of the sector and define love motels.

Design/methodology/approach

The literature review charts the development of Taiwanese love motels from a duel origin; American Motels and Japanese 'Love Hotels.' This is followed by an empirical qualitative study consisting of a two-stage collection strategy: focus groups of hospitality and tourism professionals to gather a wide range of opinions on the subject area followed by semistructured interviews with consumers.

Findings

The findings split into three interrelated areas: growth of Taiwanese love motels due to more liberal attitudes towards sexual practice; a change in the public perception of motels due to increased standards and an increased satisfaction with the personal consumption experience; these hotels are designed for couples.

Research limitations/implications

The empirical element of this study is an exploration of consumer experience in Taiwanese love hotels. Due to the sensitive nature of some of the data that was gathered a qualitative approach has been adopted.

Practical Implications

The sexual associations with this product appear almost coincidental. If the love motel product is considered in its purest form it is simply a hotel product that provides complete anonymity for its guests. Therefore, despite its application in South East Asia, this hospitality concept has potential to be applied in a variety of guises.

Originality/value

The phenomenon of 'Love Hotels' is absent from hospitality management literature; this paper begins to fill that gap by beginning a discussion on this possibly controversial sector.

\section{Key words}

Hospitality Industry; Sex; Love Hotels; Ethics; Experience Economy; Hotel Development; Hotel Design 


\section{Introduction}

'Some people in the hotel business claim they sell sex. Others believe that what they do is furnish the stage for sex. In reality, they sell sleep.' (Robinson, 1996, p. 36).

Hotels around the world perform a number of different functions, primarily the provision of food, beverage and accommodation. This paper, however, provides insight into an overlooked, but growing, sector of hotels that aims to deliver on all three of the possibilities that Robinson (1996) identifies, the Taiwanese love motel. Love hotels (Caballero \& Tsukamoto, 2006) are well established providers of specialised accommodation in Japan and have been for over 400 years. In Japan alone the Love Hotel industry is worth some 4 trillion yen and some 500 million visits are made to love hotels every year (Chaplin, 2007). Love hotels are also found in Korea, Hong Kong and, the focus of this research, the emergent and rapidly growing sector in Taiwan. This sector is separate from any concept of a so-called 'sex hotel' or brothel (Brents \& Hausbeck, 2005; Ford \& Wirawan, 2005), or part of the sex tourism industry where resident prostitutes are provided (Clift \& Carter, 2000); love hotels are for couples and not sex for hire.

The sector is omitted from many of the standard hospitality industry texts (Brotherton, 2003; Jones, 1996; Medlik, 2003); even Hing et al (1998) in a review of the hospitality sector in Asia do not refer to love hotels. This omission is, perhaps, understandable given a somewhat uneasy relationship between the bulk of the hotel market and sex. Hotels, however, also occupy a unique place in the 'social imagination of the West, in many ways they are synonymous with sex, romance and adventure' (Pritchard \& Morgan, 2006, p. 763). It is, perhaps, the sense of freedom engendered that makes hotels the ideal place for 'transgressive behaviours and illicit sex' (Pritchard \& Morgan, 2006, p. 763). These activities, at least in a Westernised context, are undertaken within a furtive, and somewhat seedy, context. In particular the link between hotel management and prostitution is well documented (Harper, 2008; Pritchard \& Morgan, 2006; Robinson, 1996) and represents, perhaps, the limits of liberalism in Western hospitality (Harper, 2008). This paper identifies a significant and rapidly expanding hotel sector that provides a formalised, commercial context for sexual activity.

\section{Japanese Love Hotels}

Love hotels are a particular type of accommodation in Japan that exist for the sole purpose of providing a private space where couples can engage in sexual intercourse. The Japanese love hotel model is the precursor to the Taiwanese love motel. Caballero and Tsukamoto (2006, p. 205) defined love hotels as establishments, 'which charge the customer by the hour and are targeted at couples for sexual intercourse, developed from the deai-chaya, tea rooms of the Edo Period, which were mostly used by prostitutes and their clients'. As Caballero and Tsukamoto $(2006$, p. 205) state, the history of love hotels can be traced back to the Edo period (1600-1868). Originally love hotels were designed in the style of tea-houses (deai-chaya) which had about 15 small rooms of around a hundred square feet each. When couples arrived in the tea-houses, their shoes and possessions would be collected as a security deposit before they paid the bill upon leaving. Customers were then led to a private room and served with some tea and snacks. After drawing a bath for the couple, service staff would leave the guests in privacy. By the early twentieth century tea houses in Japan had been replaced by two types of establishments that offered similar services, these were machiai and sobaya. Machiai were places that offered minimal facilities with tatami-mat space for private 
activities and they were especially popular in Tokyo. The other type of establishment, sobaya, were noodle restaurants equipped with rooms upstairs for rent (West, 2002). Customers could rent a room with privacy in sobaya for short periods of time. However, not all of the noodle restaurants were operated in this way and people could distinguish the differences from the signs outside like 'REAL noodle restaurant.' Both machiai and sobaya were widely utilised by prostitutes but not normally by couples (Caballero et al., 2006). Although no regulations excluded normal couples from using machiai and sobaya, the special and 'professional' atmosphere seemed to stop them from actually making use of them. Mostly male customers went to these establishments with geisha or other kinds of sexual workers. It was more typical for couples to have sex outdoors, for example, in parks (Caballero et al., 2006).

'At the beginning of the Twentieth Century, many couples made love outside. In fact, the general movement of male-female interaction from outdoors to indoors is said to be an extremely recent development' (West 2005, p. 157).

Further evidence is offered by a news report from 1916, indicating that in the evenings parks were full of couples from various social levels such as doctors and nurses or manual labourers.

Furthermore, during the U.S. Occupation, 'as the sun set, lovers gathered in places like the Imperial Palace grounds and Inokashira Park, and the next morning the grass was full of paper scraps and condoms' (West 2005, p. 159). In 1930s, enshuku (one-yen dwelling) appeared, these were the first ideal indoor facilities that couples could use for having sex. Enshuku are considered to be the operations that are most similar to modern love hotels (Caballero et al., 2006). As its name suggests, enshuku users paid only one Japanese Yen per person per hour to rent a room. Rooms were equipped with Western style furniture, double beds and locking doors, which was different from other establishments. Apart from enshuku, bathhouses were utilised as private spaces for sex as well. This trend lasted from the arrival of enshuku in the 1930s until the late 1960s (Caballero et al., 2006).

The late 1960s saw the arrival of the first love hotel and the introduction of a totally new style of establishment, characterised by the elegant interiors and sexually orientated facilities. The facilities included features such as, "electric beds, mirrored ceilings, foam-filled bathrooms, and see-through bath mirrors' (West 2005, p.159). Perhaps the epitomic establishment during the dawn of love hotels in Japan was the Meguro Emperor Hotel. This hotel boasted all the typical features associated with love hotels and impressed customers with its Disney-style appearance and architecture (Huang, 2005). It was the heavily themed departure from reality associated with love hotels that made them as successful as they were.

Due to the considerable price of land and small living space several authors (Bornoff, 1991; Pritchard \& Morgan, 2006; Richie \& Silva, 2001; West, 2005) note that it has become custom and practice in contemporary Japan for couples to have sex in hotels to guarantee anonymity and ensure privacy from relations. Today, typical characteristics of love hotels include:

- Often decorated with colourful neon and gaudy architecture, especially in more urban areas.

- Usually located near busy transit points.

- Entrances are always at the back to allow customers to enter inconspicuously.

- Doors are covered by rubber curtains to ensure the privacy of customers.

- Rooms are fully-furnished with rotating beds, mirrored ceilings, glass bathtubs and similar. 
- Themed rooms are available for a higher price.

- Strong sexual implications are evident in rooms including pornographic videos, sexual equipment and costumes.

Before 1985, there were no industry regulations particularly for love hotels, due to it being difficult to distinguish love hotels from regular hotels. Love hotels were regulated by the Inn Law which 'covered both sex-related and non-sex-related types of establishments' (West 2002, p.160). Hence, love hotels could be located in habitation areas or near schools. Many publicly-raised issues exist concerning love hotels, the main problems are listed below.

- Morality: Having sex-related establishments in public areas may have a negative influence on both children and adults.

- Crime: Due to the privacy offered by love hotels, crimes are common. These include prostitution, murder and extortion.

- Cost concern: The waste of water by taking baths or showers and the wide use of neon signs increase the cost of energy and resources.

- Minors' consumption: There are no regulations to ban minors from using love hotels. Hence smoking and sexual activity among minors occurs (West, 2002).

To solve these social problems, the Japanese government announced the revision of Entertainment Law to regulate love hotels. In West's article (2002, p.147), it is suggested that the law actually "led to an increase in love hotels (or at least did not lead to a decrease), primarily because of the narrow statutory definition of what constitutes such an establishment"

\section{The Development of Love Motels in Taiwan}

The idea and design of Taiwanese motels is a hybrid of the American motel and Japanese love hotel models. A traditional American motel, as defined by Jackle, Rogers, and Sculle (1996), is a type of highway orientated accommodation, designed specifically to cater for people in transit. Dittmer (2002, p. 453) develops this to add that a motel is, "traditionally, a type of lodging establishment that catered to travellers with automobiles and provided self-service parking on premises." However, having been influenced by a variety of factors, modern motels in Taiwan bare little similarity to their predecessors. The development of Taiwanese motels can be divided into four stages, as shown in Table 1: Four stages of Taiwanese motel development

[Table 1]

Table 1 illustrates the process of development of love motels in Taiwan. The four stages described show the manner in which corporate strategy amongst motel operators developed and changed to encompass a focus on services and facilities. As well as this, the four stages of development illustrate the influence culture and government policy have had on the motel sector. This process of 
development describes the reciprocal nature of the development whereby, to some extent, the liberalisation of sexual attitudes has influenced the greater presence of love motel products; similarly the commercialisation of love hotels has contributed to the wider acceptance of their usage in Taiwan.

In the last 20 years, as shown in Table 1, the Taiwanese love motel has rapidly developed into a significant and distinct product. The characteristics of Taiwanese motels in terms of operation can be defined by three distinct characteristics, which are location, operational mode, and target consumers. Table 2 describes these characteristics of contemporary Taiwanese motels. It shows that motels generally occupy spaces slightly outside cities due to the high prices of downtown locations. Motels stratify their prices to suit those who are using the facilities for sex and those who are using the motel for accommodation. The main target consumer groups are also described as travellers and couples with an age range of 20-39 years old. The two main target groups justify the parallel pricing strategy between short stays and overnight stays.

[Table 2]

Table 2 also shows that the Taiwanese motel has evolved over time since its inception and the variety of services and locations it caters for is reflective of the increasingly liberal attitude towards sexual engagement in the country. Lam (2003) observes that in Taiwan love hotels provide a location for prostitution but also other sexually related activity. Enjo-kōsai (compensated dating) is a practice (originating in Japan but has since spread to other eastern cultures such as Taiwan) where older men give money and/or luxury gifts to attractive women for their companionship, and possibly sexual favours.

\section{Love Hotels and the Experience Economy}

Pine and Gilmore (1999) suggest that sustainable competitive advantage can be gained by giving the customer a unique memorable experience. Pine (2008, p. 28), developing Pine and Gilmore (1999) argues that authenticity is now the central feature of the experience economy people "no longer desire the fake from some phony; they want the real from the genuine.... We want authentic commodities (such as green energy or eggs from free-range chickens), authentic goods (such as vintage clothing or natural wood pencils), authentic services (such as an exceptionally delivered meal or a ritualistic tea ceremony), and even authentic transformations (such as personal trainers that actually care about one's fitness aspirations or education suitable for the real world)."

Gilmore and Pine (2002, p. 88) when exploring how hospitality products can be differentiated by experience note that "by creatively orchestrating multiple dimensions of one's hospitality business as distinct theatrical events within an overall experience, any company can move to differentiate its offering." They suggest ways that a routine service can be turned into a memorable event and give the example of themed rooms within a hotel citing: Fantasyland Hotel in Canada with rooms varying from an Eskimo igloo to an African village; Radisson SAS offers individual room of particular design to 
cater to various guests; and the Library Hotel in New York with rooms numbered and designed around the Dewey decimal classification system. Williams (2006, p. 493) notes that where experiences are central to the consumption activity, tourism and hospitality businesses often view consumption as an internalised state and they must look beyond: "If firms are to be effective in the highly competitive tourism and hospitality industries, it is imperative that they understand contemporary markets and consumers." These contemporary markets can include both authentic experience and escapist activities. Williams (2006, p. 448) developing Pine and Gilmore (1999) describes 'escapist activities' are those activities "which involve both active participation and immersion... allowing participants to create new identities and realities for themselves;" exampling bungee jumping; water-sports or membership of volunteer organisations.

\section{The study of love motels}

Due to the absence of any research on love motels in hospitality literature a two stage data collection strategy was adopted using exploratory focus groups and semi-structured interviews. The resultant data was analysed using a template analysis method.

\section{Exploratory focus groups}

An initial stage was undertaken using focus groups, widely used for research of an exploratory nature (Morgan, 1988). Morgan states that when 'orienting oneself to a new field' focus groups are of particular use as they can generate interesting data with little contribution from the researcher (Morgan 1988, p21). Two focus groups of ten Taiwanese hospitality and tourism professionals known to one of the researchers were consulted as experts to gather opinions on the subject area (Krueger \& Casey, 2000) and draw out potential aspects of the topic which could be explored in the second stage of the process. Given the limited literature available only three a priori themes were used with focus group one. This was followed up in focus group two with a schedule addressing the emergent themes and introducing test questions which could be refined at a later stage, this ad hoc pilot approach was used due to the difficulty of getting respondents for the interviews. Focus group two was subsequently analysed and questions and probes generated for the interviews. The development of themes and questions is visualized in appendix one.Focus groups were conducted in a neutral location and were recorded using a digital voice recorder. This was subsequently transcribed for analysis of emergent themes.

\section{Semi-structured interviews}

After further refinement of the research instrument the second stage of the collection was commenced. An interview schedule was developed using the emergent themes from the focus groups and was used for each interview including relevant sub-questions and probes to allow sufficient depth and parity of information from each interviewee (Gillham, 2005). Semi-structured interviews facilitate a strong element of discovery, while the structured element allows an analysis 
of commonalities between interviews (Gillham, 2005) and were used in order that both cross-case and within-case analysis could be undertaken (Cresswell, 2007).

Twenty interviews were conducted in Taiwan with motel customers, interviewees were all between 20-39 years old; the target age identified in the literature review. Due to the potentially sensitive nature of the data to be collected approaching potential participants in any random way was deemed to be inappropriate. On this basis respondents were contacted using a snowball sampling method (Jennings, 2001). Personal contacts were used for the initial interviews and using snowball sampling other participants were contacted initially informally through the previous interviewee, thus ensuring that any potential participants could be informed of the nature of the interview by someone familiar avoiding any uncomfortable association issues. The principal requirement was that the interviewee had stayed at least once in a love motel in Taiwan in the last year. Informed consent (Miles \& Huberman, 1994) was obtained by emailing participants with information about the study giving prior warning about the type of questions that would be asked. Interviews were conducted in a range of locations, depending on the availability of the interviewee in question and ensuring the comfort of the interviewee. Normally local coffee shops or restaurants were used and this gave the appearance to the interviewee to be more of a casual chat; the interviews were not recorded to try and keep the interviewee at ease.

Although this research did not require contact with vulnerable populations such as those described by Creswell (2007) it was important that the identity of participants was protected when disseminating information (Easterby-Smith \& Lyles, 2003) and as such all interviewees were guaranteed anonymity to the extent that even in the paper the interviewees are not identified in any way.

\section{Data Analysis}

The data analysis method used was template analysis (Blum, 1997; King, 2004). Template analysis encompasses a 'group of techniques for thematically organising and analysing textual data' (King, 2004, p.256). Essentially, emergent themes are written up in a template from the data gathered during the research process. Some of the themes 'will be gathered a priori' (p256.) but may be added to as the research progresses. In the case of this research, emergent themes from the focus groups became the a priori themes and these were added to and refined after the conclusion of the second stage of the data collection process. This is consistent with the creation of a template outlined by King (2004, p.259). Once each interview was analysed relevant quotes relating to the themes from the focus groups were extracted or added to new emergent themes. The findings are organised into three broad themes covering the growth of Taiwanese motels, the changing public perception of motels, and changes in personal consumption experience. 


\section{Summary of Findings}

\section{Growth of Taiwanese Motels}

The growth of Taiwanese motels has primarily been driven by two key factors: the development of motel facilities and a more open minded attitude towards sex amongst the general population. The majority of interviewees agreed that the development of motels occurred due to an improvement in the physical environment, including the introduction of a wide range of in-room sexual facilities and exotic decorations. This point was supported by other interviewees who highlighted the multifunctionality of modern motels that attracted not only travellers but also consumers who simply wanted to relax; it was also noted that the overall standard of rooms had improved to the extent that they are comparable with five-star hotels.

All the research participants were in agreement that the increase in popularity of motels was due in part to a liberalisation of sexual attitudes amongst the wider population. People no longer felt the need to be secretive or embarrassed about sexual activity in Taiwan. One focus group participant observed that TV programmes and movies now included more sexual content. Another participant noted that there are more news reports about enjo kōsai (compensated dating) and one night stands, indicating that the young generation is more open-minded towards sex. As the previously conservative attitude towards sex has changed, people have begun to address sex more openly and it has become a regular, almost recreational activity. However, due to young married couples often still living in the family home the motels provide an alternative space that enables a higher degree of privacy.

It was noted that this new-found sexual liberation was not universal and occurred mostly amongst the under 30's. Sex before marriage is no longer considered a taboo subject, although parents and elders will not encourage it. Changes in sexual attitudes amongst the younger populous in Taiwan would appear to benefit motels in two ways. Firstly, the highly developed facilities provide a fun and stimulating environment in which to enjoy sexual activity. Secondly, the continued disapproval of older relatives means that unmarried couples still require a more private location in which to engage in such activity. Other, less significant, factors included a perception that motels provided greater value for money than hotels and the introduction of a two days off (per working week) policy that has led to increased leisure time which could be filled with motel visits.

\section{Public perception of Motels}

The image of motels described by the interviewees was an improving one although three interviewees noted that some negative connotations still exist. The improvement in image was attributed to the physical changes made in many motels and the influence of the media on decision making.

Several respondents argued that the public perception of motels has improved largely through efforts made to rid motels of their association with sex-only and cheap, low quality service. Interviewees cited facilities, physical designs, and diverse services as being the main contributing elements to a more positive image of motels. 
"People mostly associated motel to affairs or prostitution in the past. However, nowadays people can go to motels to experience the exoticism of theme rooms or spa facilities. The motel owners are also targeting different groups of consumers. Motels become not just for couples who want to have sex"

The influence of the media on consumer decisions to visit motels was discussed by several participants. In particular advertising and promotion plays an important role in creating a more positive and refined image. Using motels did not appear to be as shameful and embarrassing as it perhaps once did and it would not have to be kept a secret due to the more open-minded attitude toward sex. Instead, due to the positive media image, it can even be considered fashionable to go to motels. Advertising and promotion are so effective that motels have become synonymous with certain events and images, to the extent that "especially, on Valentine's Day or Christmas, it is like a "ritual" to go to motels as a celebration".

The positive media image was also disputed by many of the interviewees who reported negative news reports about motels, including those concerning drug use, love affairs and suicide in motels. It appears, therefore, that the influence of the media in shaping opinions of motels is not to be underestimated. All interviewees and focus group participants claimed to have been influenced by the media or by motel websites in some form or other. The images formed were largely positive although this was not always the case.

\section{Personal consumption experience}

When exploring the changing attitudes towards motels, consumers' own experiences provide valuable insights. All of the respondents have used modern style motels and four interviewees have stayed in the older style motels also.

The respondents had various preconceptions before their first motel experiences. Most of the interviewees mentioned that they were curious about the room design and facilities whilst others felt more embarrassed, for example "I didn't feel nervous because I had received much information about it. However, I was still a little embarrassed because I worried about being seen by others." This was echoed by other respondents who had concerns about exotic toys and images they might find in their room, however, this has been solved by some motels that now allow the booking of particular styles of room on-line. What was clear from all respondents was that they were in search for anonymity as much as a private space for sexual engagement. From the initial responses it would seem that love motels offered a space for romance and sexual intercourse. However, upon further discussion, space was not the only issue as the respondents made very clear their unwillingness to use a 'normal' hotel as they may be known to the staff or recognised by other guests. Therefore, the requirement for a sexual space is important but not the only issue. This alludes to possible core product design issue of love motels whereby the provision of an anonymous environment is more important than the provision of the space itself. As highlighted by the literature review, anonymity would seem to be the paramount issue, as the tradition of using public parks at night developed out of the need to be clandestine.

When considering their experiences post-consumption, most of the respondents stated that the service had exceeded their expectations. The aspects that were considered most impressive were 
the romantic or leisurely atmosphere and the facilities, including jet bath, spa, size of room and the overall level of comfort:

"The space, the interior design, the facilities were all beyond my expectation. In addition, the lighting and atmosphere were romantic and enjoyable as well"

In the case of one interviewee the lasting impression was less satisfactory as:

"Although the room was decorated, you still feel like this is a place only for having sex.

Things like TV channels that kept playing porn movies made me uncomfortable."

To explore the respondents' attitude towards using the motels and the responses they had received from others, interviewees were asked whether or not they had ever told of or discussed their motel experiences with friends or families. Most of the interviewees felt that with close friends, it was acceptable to discuss their experiences, but did not want parents or elders to know as they still tended to hold motels in a very low regard. One interviewee told her family only about an experience when she stayed in a motel with a female friend, however she did not discuss experiences with boyfriends. Only one interviewee had freely discussed motel consumption with family members.

Overall, the experiences of the respondents are consistent with a pattern; nervous prior to consumption coupled with some embarrassment but overall satisfaction with the facilities and total value for money. Despite this, there was general nervousness about discussing motel stays with anyone other than close friends suggesting that there still exists a social stigma concerning motels.

\section{Discussion on Interview Outcomes}

The phenomenon of the original love hotels in Japan and the more recent love motels, explored in this research, comes down to a question of culture. The discussions of the uses of private space and how this relates to the need for spaces such as love motels is somewhat of a falsity (Bornoff, 1991; Pritchard \& Morgan, 2006; Richie \& Silva, 2001; West, 2005). Despite the need for intimate space being cited by Lam (2003) as the reason for facilities like love motels emerging, this is possibly only half of the equation. When it is considered that the birthplace of the love hotel is Japan (Caballero et al., 2006), a country larger than the sexually liberal United Kingdom, there must exist an element other than simply space that drives the apparent necessity for such products. It would appear that the answer to this question lies in South East Asian culture. The consideration of space and sexual liberty in the public domain together, combine a more comprehensive perspective on the love hotel phenomenon. Public intimacy is strictly frowned-upon in South East Asian culture, indeed it is said that the only people one will see kissing in public in South East Asia are Western tourists. This further points to the question of such a product's viability outside this particular cultural context. When sex and intimacy are considered to be extremely private matters it is understandable why couples are reluctant to engage in sex in the family household.

Products like love motels provide anonymity, but in Western cultures anonymity does not hold currency for the general population. Therefore, it seems unlikely that the love hotel product will find a market beyond its existing host countries. Anonymity remains the pivotal factor in the future of 
the love hotel product therefore. The development of more diversified and augmented love hotel products resonates the shift in cultural attitudes amongst the younger generations in Taiwan and elsewhere in Asia. It seems that the anonymity the product once traded on moves further towards being a redundant feature as sexual attitudes evolve. However, despite the cultural necessity for love hotels showing signs of ceasing, the 'Disneyfication' of love hotel products illustrates the industry's willingness to evolve in order to continue to stimulate the market. Despite more liberal attitudes, the tradition of using love hotels and the quality of the products on offer may result in these products continuing to find success. For this reason such products could be commercially viable in other cultures if the product was targeted effectively.

Even in Western contexts there is some evidence of hotel companies using sexual messages and erotic subtext when marketing their products (Robinson, 1996; Harper, 2008). The research identifies that, despite an explicit and legitimate environment within which sexual activity and exploration can take place, there is still something of a general social stigma attached to the use of a hotel for exclusively sexual aims. Despite increased social acceptance some love hotels in Japan use a slot machine system for paying for rooms to ensure total anonymity suggesting that, despite the liberal and formalised setting, this is not considered a conventional hospitality transaction. The somewhat seedy and furtive Westernised attitude towards sexualisation in hotels and other formal settings identified earlier may suggest that the introduction of such specialised hotel product offerings in the West would be unlikely.

However, the success of this product lies in the facilitation of a taboo activity in Asian culture. This highlights the parity between love hotels and products like the 'Bunny Ranch' in Nevada, USA where a socially contentious pursuit is anonymously catered-for. However, the basic love hotel model could be arguably obsolete in a Western context due to contemporary sexual attitudes. If the appropriate consumer markets were discerned and targeted a love hotel-style product that created an otherwise unattainable venue for people to pursue taboo activities could be successful in the West. In liberal Western cultures themed love hotels with high levels of service and quality accommodation could also be successful. Indeed the techniques that have been developed to ensure guests' anonymity in the love hotel sector could be applied to a basic hotel model that ensures the anonymity of guests, something that could be of interest to businesses in what is the tabloid culture of the West.

At first glance Love Motels seem to be creating an inauthentic experience, with the themed rooms satisfying sexual desires, whimsies and caprices. Rather than catering for seedy peccadilloes, or even the darkest innermost desires, Love Motels can also be seen to provide a genuinely escapist activity (Pine and Gilmore 1999; Williams 2006) which successfully transcends authentic experience (which at the sexual level it probably is) into a truly fantastic experience; one which allows couples to enter into and explore their fantasies. Themed rooms around various sexual fantasies is probably not what Gilmore and Pine (2002, p. 88) had in mind when they suggested "multiple dimensions of one's hospitality business as distinct theatrical events", however that is exactly what the Love Hotel concept achieves whilst also creating an authentic fantasy experience. 


\section{Conclusion}

This paper has looked at the development of Taiwanese love motels that have developed from the combination of the Japanese love hotel and American motel concepts. The growth of this market in Taiwan and its economic importance in other Far Eastern countries suggests that Western interpretations of the international hotel industry should not continue to ignore this emerging sector.

The love motel industry in Taiwan has capitalised on a combination of changing attitudes and a developing difference in values between older and younger generations. This leads to questions about the longevity of the sector and concerns about the possible decline of love motels as the younger population grow up and attitudes continue to become more liberal. The apparent change in attitudes towards these products in Taiwan highlights considerable scope for further study in this field. Therefore, further research addressing issues raised in this and other work could further establish this phenomenon as an accepted area of study in the international hotel management sector. In particular, investigating how hotel customers view the product as a sexualised setting may prove valuable in ascertaining the potential for the future growth of the love hotel product.

There is potential for the love hotel product to add a new and exciting dimension to a growing industry throughout the world. However, it could be argued that Western morality may not allow the emergence of such a sector beyond the Far East. Conversely, Western morality may also be so accepting of sex that the need for such an overtly sexualized product does not exist. Since sexual attitudes are already liberal in the West (more so in Europe rather than the United States), the need for a remote space, like a love motel, to engage in sexual activity may not be required. It is space that has acted as the catalyst for the development of motels in Taiwan and space is not an issue in the West generally. The difference in attitudes between the old and the young in Taiwan has also fueled the development of love motels; but attitudes have been shown to be fundamentally different in the East from the West therefore this product may not work in the West. It is accepted in the West that hotels sell a stage for sex but the difference in the West is that sex is also available everywhere.

The paper has shown that due to space and more so generational differences sex and sexually related pursuits cannot be accessed readily in Taiwan thus love motels cater for this need. However, in the West people do not necessarily need to pay for a location where they can view pornography, sleep with prostitutes, partners or even their spouses to nearly the same extent as they do in Taiwan. It seems that society's attitude currently feeds the market for the love motel product in Taiwan but as the new generation takes over will the demand for motels die-out? Perhaps further research or even the passage of time will prove whether motels and love hotels in general have simply been a stop-gap during a shift in attitudes in the East; or if they will become an inherent aspect of Oriental culture. 


\section{References}

Bornoff, N. (1991). Pink Samurai: Love, Marriage \& Sex in Contemporary Japan. London: Grafton Books.

Brents, B. G., \& Hausbeck, K. (2005). Violence and legalized brothel prostitution in Nevada: examining safety, risk, and prostitution policy. Journal of Interpersonal Violence, 20(3), 270295.

Brotherton, B. (2003). International Hospitality Industry: Structure, Characteristics and Issues. Oxford: Butterworth-Heinemann.

Caballero, J. A., \& Tsukamoto, Y. (2006). Tokyo Public Space Networks at the Intersection of the Commercial and the Domestic Realms Study on Dividual Space. Journal of Asian Architecture and Building Engineering, 5(2), 301-308.

Chaplin, S. (2007). Japanese Love Hotels: A cultural history. London: Routledge.

Clift, S., \& Carter, S. (Eds.). (2000). Tourism and Sex: Culture, commerce, and coercion. London: Pinter.

Cresswell, J. W. (2007). Qualitative Inquiry and Research Design: Choosing Among Five Approaches. Thousand Oaks: Sage.

Dittmer, P. R. (2002). Dimensions of the Hospitality Industry. Canada: John Wiley \& Sons.

Easterby-Smith, M., \& Lyles, M. (2003). The Blackwell handbook of organizational learning and knowledge management. Malden, MA: Blackwell Publishing.

Ford, K., \& Wirawan, D. N. (2005). Condom use among brothel-based sex workers and clients in Bali, Indonesia. Sexual Health, 2(2), 89-96.

Gilmore, J. H., \& Pine, B. J. (2002). Differentiating Hospitality Operations via Experiences: Why Selling Services Is Not Enough. Cornell Hotel and Restaurant Administration Quarterly, 43(3), 87-96.

Harper, S. (2008). 'When You Walk Through These Doors, You Can Be Anything You Want': Authenticity, Fantasy and Neoliberal Ideology in Hotel Babylon. Journal of British Cinema and Television, 5(1), 113-131.

Hing, N., McCabe, V., Lewis, P., \& Leiper, N. (1998). Hospitality trends in the Asia-Pacific: a discussion of five key sectors. International Journal of Contemporary Hospitality Management, 10(7), $264-271$.

Hsu, T. M. (2003). Wego Legend. Taipei: Keetai Management.

Hwuang, S. C. (2004). The Study of Motel Market Segmentation and Sensation Seeking Scale. Chinese Culture University, Taipei.

Jakle, J. A., Sculle, K. A., \& Rogers, J. S. (1996). The Motel in America. Baltimore, MD: Johns Hopkins University Press.

Jennings, G. (2001). Tourism Research. Australia: John Wiley and Sons Ltd.

Jones, P. (1996). Introduction to Hospitality Operations: Cassell.

Krueger, R. A., \& Casey, M. A. (2000). Focus Groups: A Practical Guide for Applied Research. London: Sage.

Lam, O. W. (2003). Why did enjo kosai anchor in Taiwan but not in Hong Kong? Or the convergence of "enjo" and "kosai" in teenage sex work. Inter-Asia Cultural Studies, 4(4), 353-363.

Medlik, S. (2003). Dictionary of Travel, Tourism and Hospitality: Butterworth-Heinemann.

Miles, M. B., \& Huberman, A. M. (1994). Qualitative Data Analysis. Thousand Oaks: Sage.

Pine, B. J. (2008). Interview with B. Joseph Pine II: Interview by Rachel Brown Strategic Direction 24(1), 28-31.

Pritchard, A., \& Morgan, N. (2006). Hotel Babylon? Exploring hotels as liminal sites of transition and transgression. Tourism Management, 27(5), 762-772. 
Richie, D., \& Silva, A. (2001). The Donald Richie Reader: 50 Years of Writing on Japan Berkeley CA: Stone Bridge Press.

Robinson, J. (1996). The Hotel: Upstairs, Downstairs in a Secret World: Simon \& Schuster.

West, M. D. (2005). Law in Everyday Japan: Sex, Sumo, Suicide, and Statutes. Chicago University of Chicago Press.

Williams, A. (2006). Tourism and hospitality marketing: fantasy, feeling and fun International Journal of Hospitality Management, 18(6), 482-495. 


\begin{tabular}{|l|l|}
\hline \multicolumn{2}{|c|}{ Table 1: Four stages of Taiwanese motel development } \\
\hline $\begin{array}{l}\text { Stage 1. } \\
\text { motels import of American }\end{array}$ & $\begin{array}{l}\text { 'Hotel California,' first motel in Taiwan opened in 1988, copying design of } \\
\text { American motels. Other motels copied this example. First generation } \\
\text { motels were mostly wooden with poor facilities; located at highway } \\
\text { interchanges. Focused on the protection of privacy. }\end{array}$ \\
\hline $\begin{array}{l}\text { Stage 2. } \\
\text { The mixture with local }\end{array}$ & $\begin{array}{l}\text { In the 1990s, interior design and cleanliness was emphasized. Offered } \\
\text { accommodation that was cheaper than hotels but comfortable and clean } \\
\text { as well. Price was higher than first generation motels. Jet baths were a } \\
\text { popular addition. Design was typically a two-level building with many } \\
\text { units. Ground floor was a garage with rooms above. Operation style } \\
\text { similar to Japanese love hotels, offering a private space for couples. } \\
\text { Locations expanded to state roads and quiet streets in towns. }\end{array}$ \\
\hline $\begin{array}{l}\text { Stage 3. } \\
\text { elements of love hotels }\end{array}$ & $\begin{array}{l}\text { Two-days-off per week policy implemented in Taiwan in 1998. Domestic } \\
\text { tourism suddenly became prosperous. In reaction to competition motels } \\
\text { improved in terms of interior, facilities, and service quality. Elements of } \\
\text { Japanese love hotels like luxurious themed rooms were widely } \\
\text { introduced. Rooms had double-sized jet baths and large TVs as standard. } \\
\text { Price was lower than a five-star hotel. Newly opened motels were } \\
\text { situated in business areas and residential areas in cities. }\end{array}$ \\
\hline $\begin{array}{l}\text { Stage 4. } \\
\text { New generation of } \\
\text { motels }\end{array}$ & $\begin{array}{l}\text { Emphasis on luxury replaced by leisure and lifestyle orientated } \\
\text { properties. Interior design became modern and simple with evident } \\
\text { consideration for fashion. Due to public's more liberal attitude towards } \\
\text { sex, operators started to spend money on advertising. Popular locations } \\
\text { for new motels were suburban areas of cities. }\end{array}$ \\
\hline
\end{tabular}

Source: Adapted from Hsu (2003) 


\begin{tabular}{|l|l|}
\hline \multicolumn{2}{|c|}{ Table 2: Characteristics of Taiwanese motels } \\
\hline Characteristic & Description \\
\hline Location & $\begin{array}{l}\text { Price of land in cities is expensive. Downtown hotels struggle to justify big spaces. } \\
\text { As a result, many motels are opened in suburban areas, taking advantage of better } \\
\text { traffic and cheaper land. }\end{array}$ \\
\hline $\begin{array}{l}\text { Operational } \\
\text { mode }\end{array}$ & $\begin{array}{l}\text { Two kinds of service: rest or overnight-stay. 'Rest' means to stay for two or three } \\
\text { hours. An overnight stay is counted as twelve hours. Mostly motels focus on the } \\
\text { rest consumption as the room turnover is higher than that of overnight-stays. To } \\
\text { customers the convenience of renting a room for several hours and paying less is } \\
\text { attractive. However, Overnight guests often seek breakfast and dining services } \\
\text { which can increase their spend. }\end{array}$ \\
\hline $\begin{array}{l}\text { Target } \\
\text { consumers. }\end{array}$ & $\begin{array}{l}\text { Mainly two groups of people: travellers with cars who primarily stay overnights } \\
\text { and couples who seek private places for having sex. Couples are the main rest } \\
\text { consumption group according to Huwang's database built up in his research. The } \\
\text { public attitude toward sex is becoming more open-minded according to Huwang } \\
\text { (2004) and, the majority of motel customers are from 20-39 years old, most of } \\
\text { whom are unmarried. }\end{array}$ \\
\hline
\end{tabular}

Source: Adapted from Hwuang (2004) 